\title{
The Analysis of New Weapon Equipment Training and the Research of Teaching System
}

\author{
Yue Chun-guo ${ }^{\mathrm{a}} *$; He Hua-feng ${ }^{\mathrm{b}}$; Zhang Xinc; Guan Wen-liang ${ }^{\mathrm{d}}$; Zhou Tao ${ }^{\mathrm{e}}$ \\ Xi'an Hongqing High-Tech Research Institute, Xi'an, Shaanxi , China \\ a*63627326@qq.com \\ bhhf0903@163.com \\ c49278157@qq.com \\ d7131647@qq.com \\ e50863907@qq.com
}

\begin{abstract}
The world military has entered the era of information war. With the rapid development of science and technology, more and more new missile weapons with complex technology, principle and highly integrated products have been installed in the combat forces. At the same time, the military academies have carried out greater system adjustment and reform. In this context, the current military academies' new missile weapons training has many new features And face a series of new problems. In view of the new characteristics and new problems faced, the model chief division team actively meets the needs of the grass-roots combat forces and through many years of teaching practice exploration, proposes to solve new problems from the aspects of education concept, teaching content, teacher construction and teaching condition guarantee, and finally creates a set of scientific, practical and operable post training teaching system for the combat department The rapid formation of the combat effectiveness of the team has played a very good role in promoting the reform of post training education in military colleges and universities.
\end{abstract}

Keywords: new type missile weapon, job training, problem analysis, teaching system

\section{新型武器装备任职培训问题分析与教学体系研究}

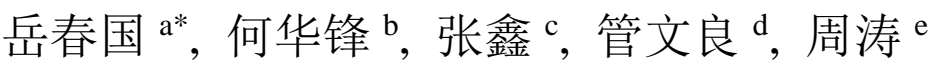

西安洪庆高科技研究所, 陕西西安, 中国

a*63627326@qq.com

bhhf0903@163.com

c49278157@qq.com

d7131647@qq.com

e50863907@qq.com

\section{摘要}

世界军事已经进入信息化战争时代, 随着科技的快速发展, 越来越多技术、原理复杂以及产品高度集 成的新型武器装备列装到作战部队, 同时军队院校进行了较大的体制编制调整改革, 在此大背景下当 前军队院校新型武器装备任职培训呈现出许多新特点并且面临着一系列新问题。针对新特点及所面临 的新问题, 教员队伍积极与基层作战部队对接需求并经过多年的教学实践探索, 提出从教育理念、教 学内容、师资建设和教学条件保障等方面应对解决新问题, 最终打造起一套科学性、实用性以及可操 作性强的任职培训教学体系, 为作战部队战斗力的快速形成起到了很好的推动作用, 其成果对于推进 军队院校任职培训教育改革提供了很好的借鉴意义。

关键词：新型武器装备；任职培训；问题分析；教学体系 
的培养; 另外，新型武器装备任职培训周期和培训时间 相比学历教育更短。推进军队院校任职教育转型和发展, 必须深刻理解其内涵和本质, 以岗位需求、紧贴部队、 强化实践为目标, 树立鲜明的办学理念。

2) 现有教学内容与新型武器装备任职培训需求不 适应

教学内容直接影响着受训对象的知识、能力和素质 结构, 合理确定任职教育的教学内容是军队院校教学工 作的一个核心问题。教学内容体现了军队院校任职教育 的培养目标和部队发展对军官人才素质的基本要求。目 前, 由于新导弹武器型号更新换代很快, 导致新武器型 号任职培训的教学内容体系构建得还不够合理, 直接影 响了教学质量。首先, 教学内容设置针对性不强, 教学 内容散而杂, 教学内容的面广点多, 只有广度没有深度。 其次, 教学内容既要考虑学科基础, 也要考虑知识、技 术更新的要求来设置具体内容, 以适应作战需求。最后, 教学内容课程结构比较单一, 教学内容理论基础模块课 程比重大, 以提高岗位关键能力的实践内容较少, 教学 内容的指向性、实用性和时效性有待加强。军队院校任 职教育教学内容必须以部队需求为牵引, 以提高军官任 职能力为根本目的。如何根据部队实际需求和军官能力 构成建立起现代化的军官任职教育内容体系, 是提高军 官任职教育质量必须解决的现实问题 ${ }^{[1-3]}$ 。

3）教员教学水平与新型武器装备任职培训需求不 适应

新型武器装备任职培训的教员队伍建设没有摆脱 学历教育的束缚。首先, 多数教员缺乏部队任职经历, 教员队伍在知识结构、学历结构和职称结构上需要进一 步优化。另外, 承担新型武器装备任职教育的教员不仅 要精通本专业的知识, 还要具备与人才培养不可分割的 相关专业领域的知识和实践知识。对于多学科和多专业 交叉渗透的新理论、新技术、新保障法为主的教学内容, 多数教员还存在讲解不透彻和操作不精准的问题。最后, 为了适应军队院校新型号任职教育改革的需要, 提高任 职教育质量, 还要努力培养建设一支高素质教员队伍。

4）教学保障条件与新型武器装备任职培训需求不 适应

教学保障条件建设是提高新型号任职教育水平和 人才培养质量的重要保证和支撑。良好的教学保障直接 影响军队院校的办学水平和人才培养质量。教学保障基 本条件包括课程建设、教学装备建设和信息资源建设。 目前, 任职院校教学保障条件建设仍然没有摆脱学历教 育的模式, 过于强调了教学内容的学科系统性, 课程设 置创新性和针对性不强。另外, 大部分任职院校在过于 强调实践技能教学的同时, 往往忽视了基础理论知识的 教学。这种方式不利于学员改革创新能力的培养, 也不 利于面向部队工作岗位学员自身能力提升的现实需要。 最后, 目前任职院校的教学装备建设水平和信息化建设 水平, 能够为部队服务的能力水平还不高。实验室建设 以基础理论验证为导向, 装备实操与维护、岗位环境模 拟综合化的新型教学保障体系投入不足，综合运用信息 化技术、模拟仿真技术等现代化教育技术含量比较低。 


\section{4. 打造科学的新型武器装备任职培训体系}

针对以上新型武器装备任职培训的特点以及培训 过程中存在的问题, 教员队伍与作战部队密切沟通, 了 解需求, 同时主动作为收集各种资料和教学资源, 从教 学理念、教学内容、师资理论以及教学资源四个方面入 手, 最终打造出一套科学性、实用性以及可操作性强的 新型武器装备任职培训体系。

1) 做好顶层设计, 树立鲜明的教学理念

任职院校要把教育服务部队融入任职教育, 把满足 向军事斗争准备和作战部队保障需要作为为部队服务 的重点, 把贴近部队创新军事理论作为提高为部队服务 水平的关键点, 特别是更新教育理念, 作为增强为部队 服务的创新源。新型武器装备任职教育是为了解决培训 学员岗位任职能力的问题, 是一种岗位指向性很明确的 教育模式。因此, 任职院校在实施培训过程中要围绕任 职岗位所要求的知识、能力以及素养各个方面, 制订培 养目标和培养方案, 以达到提高学员岗位任职能力的目 的。另外, 军队院校任职教育培训对象主要是在职军官 或者军官, 新武器型号任职培训主要是为了任职需要, 是为了解决岗位任职能力问题, 而不是解决学员学历层 次问题。因此, 新型武器装备任职教育应该突出任职的 特点, 以部队训练任务为牵引, 应更注重岗位任职需要 建设, 同时兼顾学科体系建设。一方面要满足培训对象 未来发展的需要, 另一方面还要适应部队岗位和武器装 备发展需要, 不断为部队提供高层次军事应用型人才。

2) 紧贴部队岗位任职需求, 科学创新教学内容

合理确定教学内容是任职教育教学的一个核心问 题, 因为教学内容直接影响着受训对象的知识、能力和 素质结构。加快军队院校任职教育的教学改革需要解决 很多问题, 深化改革创新教学内容对推进任职教育教学 发展至关重要。随着任职教育转型发展, 强烈需要动态 更新任职教育教学内容, 完善新武器型号任职培训课程 体系, 发展具有任职特色的学科专业。军队院校任职教 育要强化教为战、研为战的意识, 从实战出发, 及时调 整改革专业方向, 创新教学内容, 着力增强学员岗位意 识和岗位任职能力。教学内容要紧贴战时部队需要, 动 态更新体现部队建设、作战训练、装备发展的最新成果, 有针对性地开展教学。

3) 多种渠道建设强大的师资力量

教员队伍的知识能力和素质结构直接决定了院校 的人才培养质量。新型武器装备任职教育培训对象多元 性和岗位指向性的特点, 要求任课教员必须具备良好的 知识更新能力和综合运用能力。任职教育主要是为未来 战争做准备, 教员要注重知识的储备, 不仅要有丰富的 专业领域知识储备, 还要不断拓宽知识领域, 不断加强 相关领域的学习研究。另外, 教员还要不断提高自身的 实践技能和知识综合应用能力。教员在教学过程中要把 理论知识积极运用到实践教学环节, 有效地解决学员任 职岗位中面临的实践问题, 不断提高学员的岗位任职能 力 $^{[4]}$ 。

最后, 新型武器装备任职教育教员队伍建设, 还要 利用现在的学科优势和资源, 加强教员队伍整合和能力
培养。院校从优化教员队伍整体组织结构入手, 这是任 职教育教员队伍建设努力的主要方向。首先要从优化教 员队伍结构入手，建设一支 “三师型” 的教员队伍。讲 师型教员要有较强的理论讲授能力, 主要承担理论性、 专业性、基础性较强的教学任务, 以院校教员为主; 工 程师型教员主要承担部队实践方面的教学任务, 以选调、 借调部队具有一线工作经验的教官为主; 外聘专家型教 员队伍的组成则主要是以聘请工业部门、军队著名专家 学者为主。

4) 依托各种资源加强教学保障条件建设

任职院校要创新发展, 必须要加强教学保障条件的 系统配套建设, 优化配置现有的教育训练资源。首先, 教学条件建设要向实战化战场保障建设转变, 按照装备 实操与维护、岗位环境模拟、专业技能训练与考核相结 合的思路, 建设多功能、综合化的新型教学保障体系。 其次, 在学科专业体系建设上, 要以超前的意识, 不断 调整和优化学科专业设置和教学内容, 把部队建设急需 人才的培养, 促进部队战斗力、保障力形成作为学科专 业建设的重点。最后, 在信息资源建设上, 着力提高教 学研究能力和信息服务水平, 加快硬件改善配套和资源 更新扩充, 为推进学科专业教学研究提供高效的网络平 台和丰富的信息资源 ${ }^{[5]}$ 。

\section{5. 结束语}

经过多年的探索和实践, 教员队伍所提出的从教育 理念、教学内容、师资建设和教学条件保障等方面打造 的科学性、实用性以及可操作性强的任职培训教学体系, 为部队快速培养了大量指技合一的高素质人才, 很好地 推动了作战部队战斗力的快速形成, 其成果对于推进军 队院校任职培训教育改革提供了很好的借鉴意义。

\section{REFERENCES}

[1] Lin Hai, he Jia, Luo Changkun. Characteristics of Russian military preventive medicine vocational education and training and Its Enlightenment to our army [J]. Chinese higher medical education, 2012,15 (12): 120-121

[2] Zhang Jun, Liu Peitao. Some thoughts on the innovation of post education in military academies [J]. Chinese out of school education, 2011,12 (6): 33-34

[3] Ding Xiangli, Gao Huameng, Zhu Xiaocui, et al. The main methods and Enlightenment of US military Vocational Education [J]. Continuing education, 2011, (12): 56-57

[4] Li Baogang, Ma Dengwu. Exploration and practice of vocational education curriculum construction to adapt to equipment development $[\mathrm{J}]$. China Science and 
technology information, 2011,5 (13): 134-135

[5] Shen Qiuhua, Wang Xiaojie, Wang Liqiang, Li Xiaojing. Shen Qiuhua, Wang Xiaojie, Wang Liqiang, Li Xiaojing [J]. Education and teaching forum, 2019,11 (51): 231-232 